\title{
The prevalence of intestinal helminthic infections and associated risk factors among school children in Babile town, eastern Ethiopia
}

\author{
Girum Tadesse
}

\begin{abstract}
Background: The effective prevention and control of intestinal helminthic infections requires the identification of local risk factors, particularly among high-risk groups.

Objectives: To determine the prevalence and associated risk factors of intestinal helminthic infections among school children.

Methods: A cross-sectional study, involving 415 schoolchildren, techniques was conducted between May and June of 2001. Interviews, observation, and anthropometric indices assessment were used to identify the risk factors. Stool specimens were examined using the formal ether concentration technique. Data were analysed done using the SPSS statistical software.

Results: Nine species of intestinal helminths were identified with an overall prevalence of $27.2 \%$ (113 of 415 children). The predominant parasites involved were Hymenolepis nana $42(10.1 \%)$ and hookworm $28(6.7 \%)$. In this study, the prevalence of Schistosoma mansoni was determined to be $4.3 \%$, which contrasts with the prevalence of $43 \%$ reported previously for schoolchildren in Babile town. Prevalence of intestinal helminthic infections was not related to the availability, type and usage of latrines ( $>>0.05)$. A higher prevalence of $H$. nana was found among children with poor personal hygiene $(\mathrm{p}<0.05)$. Prevalence of hookworm infection rate was significantly lower in children who wore shoes regularly $(\mathrm{p}<0.05)$. It seems that children who eat food items sold on the street had a higher prevalence of Ascaris lumbricoides and Trichuris trichiura infections than those who didn't $(\mathrm{p}=0.05)$. Children with stunted growth had higher infection rate of with $H$. nana than children who are properly nourished $(\mathrm{p}<0.05)$.
\end{abstract}

Conclusion: Intervention programs should emphasise proper personal and environmental hygiene practices. [Ethiop.J.Health Dev. 2005;19(2):140-147]

\section{Introduction}

Parasitic infections, particularly intestinal helminths, cause hundreds of thousands of avoidable deaths each year, and are among the world's most common infectious diseases. Intestinal helminths are more prevalent throughout the tropics, especially among poor communities. Records show increasing trends in helminthiasis infections, particularly in developing nations (1-4).

School age children are one of the groups at high-risk for intestinal parasitic infections. The adverse effects of intestinal parasites among children are diverse and alarming. Intestinal parasitic infections have detrimental effects on the survival (5), appetite, growth and physical fitness (6), school attendance, (7) and cognitive performance (8) of school age children.

Studies from Brazil (9) and Mexico (10) have shown the influence of intestinal parasitic infections on the anthropometric indices of school age children. To the contrary, a study done in Ethiopia among under-five children has indicated that there is no significant association between malnutrition and intestinal parasitic infections (11). Moreover, the interaction between intestinal helminthic infections and anthropometric indices is not well studied for Ethiopian school age children.

In Ethiopia the prevalence and distribution of intestinal helminths varies from place to place (12-18). Except for the Schistosoma mansoni prevalence survey conducted in 1989 no other information is available regarding the present study area (14). Thus, the objectives of this study were to determine the prevalence of intestinal helminthic infections, to identify associated risk factors and to assess the nutritional status of school children in Babile town.

\section{Methods}

This cross-sectional study was conducted among 415 school children in Babile town. The town is located about $557 \mathrm{Km}$ from Addis Ababa. It is situated in eastern Hararghe Zone between two nearby towns named: Harar and Jijiga. Babile town is situated at an altitude of 1650 meters above sea level. The town has a small stream and many small ponds. These predispose the children to water-borne diseases during swimming, washing, playing, and crossing the water. According to the 2000/01 estimates Babile's population was approximately 11,709 , with a male to female ratio of 1:1.02. During 1999/2000, more than half of all residents the $(53.3 \%)$ had accesses to tap water. Detailed

Department of Microbiology and Virology, Institute for Medical Biology, Medical Faculty, University of Tromsø, Breivika, N-9037, Tromsø, Norway; Department of Medical Laboratory Technology, Faculty of Health Sciences, Alemaya University, P.O. Box 138, Dire Dawa, Ethiopia 
information about the study area is presented elsewhere $(19,20)$.

The research was conducted at the Babile Elementary and Junior Secondary School. Among the seven schools found in the woreda (District), this school is the located at the center most spot and is thus the most accessible site for the study. At the time of the survey (May to June 2001), attendance at the school was 1,388 .

Four hundred twenty two schoolchildren were chosen to participate in the study and the sample size (n) was estimated using the statistical formula- $p(1-p) z^{2} / d^{2}$ (21). This gave a sample size of 384 . Since the overall prevalence rate $(\mathrm{p})$ of intestinal parasites was not known for the study area, $\mathrm{p}$ was taken to be $50 \%$. For the calculation, a 95\% confidence interval (z) and a 5\% margin of error (d) were used. To minimize errors arising from the likelihood of non compliance, ten percent of the sample size was added to the normal sample.

To select the sample children, the students were first stratified according to their educational level (grade 1 to grade 7). A quota was then allocated for each grade and each class room. Finally, the sample children were selected using systematic random sampling techniques by using class rosters as the sample frame.

A pre-tested questionnaire based on known risk factors was developed and modified (The questions are listed on Tables 2 and 3). Data were collected by the year 2001 graduating class students the Health Sciences Faculty of Alemaya University, who were selected \& trained for the purpose. To ensure reliable information, the children were interviewed in their mother tongues.

The interview included information such as age, family size, source and storage conditions of drinking water, existence of latrines in their homes, and yes or no choice questions for common signs and symptoms of parasitic infections during the past month. At the time of conversation, interviewers also inspected whether the fingernails of the students were trimmed and their foot wear. At the end of the day all the questionnaires were checked for accuracy and completeness.

The children were supplied with labelled plastic containers, waterproof papers, and applicator sticks, and instructed to bring proper stool samples the next day. All the specimens were them checked for their label, quantity, time, and procedure of collection. Samples that complied with the study were emulsified in a $10 \%$ formalin solution and transported to Alemaya University. Stool examinations were done using the formal ether concentration technique, which is considered as the most sensitive for most intestinal helminths (2). Medical laboratory technologists and technicians examined the samples, and ten percent of them were randomly selected and rechecked blindly to ensure quality control.

The children's barefoot stature was recorded to the nearest $0.1 \mathrm{~cm}$. For accurate measurement, a calibrated ruler was fixed on to the wall and a thin wooden plate was placed above the heads of the children, perpendicular to the fixed ruler. Weight measures were taken to the nearest $0.5 \mathrm{~kg}$ without shoes and with minimum clothing. To assure the quality of the data, the portable weighing machine was standardized regularly.

Interpretation of the anthropometric indices was done following the Gorstein et al (22) guideline. Weight-forheight (WHZ), which is used to identify children with wasted growth, was computed for all boys of ages of 11.5 years or less and heights of less than $145 \mathrm{~cm}$. Similarly, WHZ was calculated for girls younger than 10 years old and heights less than $137 \mathrm{~cm}$. Height-for-age (HAZ) and weight-for-age (WAZ) ratios were used to diagnose children with stunted and underweight growth, respectively, and both of the indicators were determined for schoolchildren younger than 18 years old.

SPSS, Windows version 11 was used for data analysis (23). Anthropometry indices were computed using the calculator mode of anthropometry calculating software program Epi Info version 6. Wasting, stunting and underweight are defined as $\mathrm{Z}$ score values of less than -2 SD (Standard Deviation), which is below what is expected on the basis of the international growth reference scale (24). Descriptive and inferential (chisquare) statistical tests were used. The significance of the differences in frequency distribution was tested by using chi-square analyses. P-values less than 0.05 were considered statistically significant.

\section{Results}

A total of 422 schoolchildren were invited to participate and $415(98.3 \%)$ provided proper stool samples and complete information. Among these, 271 (65.3\%) were males and $144(34.7 \%)$ females. The mean age of the children was 11.2 years.

Nine species of intestinal helminths were identified with an overall prevalence of $27.2 \%$ (113 out of 415 children). The predominant parasite involved was $H$. nana which was observed in $42(10.1 \%)$ of the students followed by hookworm in $28(6.7 \%)$ and S. mansoni in 18 of the students $(4.3 \%)$ (Table 1). The prevalence of Soil Transmitted Helminths (STH) was $14.2 \%$ (59 out of 415 students). There was no discrepancy on the stool examination results between the first and the quality control test. 
Table 1: Prevalence of intestinal helminths among Babile town schoolchildren, Eastern Ethiopia, 2001

\begin{tabular}{lccc}
\hline Parasite species & $\begin{array}{c}\text { Males } \\
\mathbf{n = 2 7 1} \\
\text { No }(\%)\end{array}$ & $\begin{array}{c}\text { Females } \\
\mathbf{n = 1 4 4} \\
\text { No }(\%)\end{array}$ & $\begin{array}{c}\text { Both sex } \\
\mathbf{n = 4 1 5} \\
\text { No (\%) }\end{array}$ \\
\hline Hymenolepis nana & $28(10.3)$ & $14(9.7)$ & $42(10.1)$ \\
Hookworm & $19(7)$ & $9(6.3)$ & $28(6.7)$ \\
Schistosoma mansoni* & $17(6.3)$ & $1(0.7)$ & $18(4.3)$ \\
Ascaris lumbricoides & $7(2.6)$ & $9(6.3)$ & $16(3.9)$ \\
Trichuris trichiura & $10(3.7)$ & $5(3.5)$ & $15(3.6)$ \\
Enterobius vermicularis & $5(1.8)$ & $1(0.7)$ & $6(1.4)$ \\
Taenia species & $4(1.5)$ & $1(0.7)$ & $5(1.2)$ \\
Strongyloides stercoralis & $4(1.5)$ & - & $4(1)$ \\
Hymenolepis diminuta & $1(0.4)$ & - & $1(0.2)$ \\
Overall prevalence & $78(28.8)$ & $35(24.3)$ & $113(27.2)$ \\
\hline
\end{tabular}

* The difference was statistically significant $(p<0.05)$.

The double intestinal helminthic infection rate was formed to be $4.1 \%$ ( 17 out of the 415 children), $23.5 \%$ of which were infected with a combination of $H$. nana and hookworms. Two of the 415 children $(0.5 \%)$ of the whole had triple and quadruple infections.

Tap water supply was the major source $(98.5 \%)$ of water for domestic purposes. Three hundred eighty (91.6\%) of the students' families stored their water in lid-covered containers (usually jelly cans). Two hundred sixty-two $(63.1 \%)$ of the students' households had latrines, 85 $(20.5 \%)$ used public latrines, and the remaining 68 $(16.4 \%)$ defecated in the open fields. Still, of the 347 children with access to latrine facilities, 47 (13.5\%) of them or their family members defecated in open fields. The pit latrines found in the school compound were clean and were used properly.

Four hundred eight $(98.3 \%)$ of the children regularly practiced hand washing before meals, but 67 (16.1\%) of them didn't know the purpose. Two hundred seventy-one $(65.3 \%)$ and $302(72.8 \%)$ of the children didn't trim their right and left-hand fingernails, respectively. Two hundred eighty-nine $(69 \%)$ of the children had dirt in their right-hand fingernails, and all of them were righthanders.

Children in grades one to three had higher prevalence of overall intestinal helminthic infection than those in grades 4 to $7 \quad(p<0.05)$. The prevalence of intestinal helminthic infection was not related to the availability, type and usage of latrines $(\mathrm{p}>0.05)$ (Table 2). Further analyses of the data showed that intestinal helminthic infection was independent of family size, ethnicity, or address of the children $(p>0.05)$ (Data available on request).

Two hundred thirty-four $(56.4 \%)$ of the children used to eat street food available around the school compound. Children who consumed street foods had a higher prevalence of $A$. lumbricoides and $T$. trichiura infections than those who didn't but the difference was not statistically significant $(\mathrm{p}=0.05)$.

Analyses of local risk factors for the dominant parasite showed a higher rate of $H$. nana among children who didn't wash their hands regularly before meals $(\mathrm{p}<0.05)$. Similarly the prevalence of H.nana was higher among children who didn't know the purpose of washing $(\mathrm{p}<0.05)$. A higher prevalence of $H$. nana was found in schoolchildren from families who stored their water in uncovered containers that had wide openings $(p<0.05)$. In comparison with other groups, children in grades 1 to 3 and age 5 to 9 years were affected more by $H$. nana $(\mathrm{p}<0.05)$. The prevalence of H. nana among children who had access to latrines was not different from children without access to latrines ( $\mathrm{p}>0.05)$.

Three hundred ninety-seven $(95.7 \%)$ of the children had shoes and 207 (52.1\%) of them wore shoes regularly. At the time of the interview, $58(14.6 \%)$ of them weren't wearing shoes, while $226(66.7 \%)$ of them wore flip-flop type shoes. The difference in the prevalence rate of hookworm infection between those with and without shoes was not statistically significant $(\mathrm{p}>0.05)$. Similarly, there was no significant difference between the type of shoes and hookworm infection rates $(p>0.05)$. However, the prevalence rate of hookworm infection was significantly lower in children who wore shoes regularly $(\mathrm{p}<0.05)$ (Table 3).

The prevalence rate of $S$. mansoni infection among the children was $4.3 \%$ (18 out of 415). Boys had higher prevalence of $S$. mansoni infection rate than girls $(\mathrm{p}<0.05)$. The rate of $S$. mansoni infection increased linearly with age from $1.8 \%$ for age 5 to 9 years, $4.3 \%$ for age 10 to 14 years, and $11.6 \%$ for age 15 to 19 years old. However, the observed differences were not statistically significant $(\mathrm{p}>0.05)$. Of the $18 \mathrm{~S}$. mansoni infected children, six (33.3\%) had never travelled outside Babile town and seven $(38.9 \%)$ of the infected children had a history of frequent contact with streams and ponds found in the town. 


\begin{tabular}{|c|c|c|c|c|c|}
\hline \multirow[t]{2}{*}{ Risk factors } & \multicolumn{3}{|c|}{ Intestinal helminth(s) } & \multirow[b]{2}{*}{$x^{2}$} & \multirow[b]{2}{*}{ P-value } \\
\hline & $\begin{array}{c}\text { Yes } \\
\text { № (\%) }\end{array}$ & $\begin{array}{c}\text { No * } \\
\text { № (\%) }\end{array}$ & $\begin{array}{l}\text { Total } \\
\text { No }(\%)\end{array}$ & & \\
\hline \multicolumn{6}{|l|}{ Sex } \\
\hline Male & $78(28.8)$ & $193(71.2)$ & $271(100)$ & & \\
\hline Female & $35(24.3)$ & $109(75.5)$ & $144(100)$ & 0.95 & 0.32 \\
\hline \multicolumn{6}{|l|}{ Age group } \\
\hline $5-9$ & $34(30.6)$ & $77(69.4)$ & $111(100)$ & & \\
\hline $10-14$ & $66(25.6)$ & $19(74.4)$ & $258(100)$ & & \\
\hline $15-19$ & $11(25.6)$ & $32(74.4)$ & $43(100)$ & & \\
\hline $20-24$ & $2(66.7)$ & $1(33.3)$ & $3(100)$ & 3.42 & 0.33 \\
\hline \multicolumn{6}{|l|}{ Religion } \\
\hline Muslim & $27(23.5)$ & $88(76.5)$ & $115(100)$ & & \\
\hline Christian & $86(28.7)$ & $214(71.3)$ & $300(100)$ & 1.13 & 0.28 \\
\hline \multicolumn{6}{|l|}{ Educational level } \\
\hline $1-3$ & $78(31.5)$ & $170(68.5)$ & $248(100)$ & & \\
\hline 4-7 & $35(21)$ & $132(79)$ & $167(100)$ & 5.55 & 0.01 \\
\hline \multicolumn{6}{|l|}{ Water source } \\
\hline Pipe & $112(27.4)$ & $297(72.6)$ & $409(100)$ & & \\
\hline River & - & $4(100)$ & $4(100)$ & & \\
\hline Well & $1(50)$ & $1(50)$ & $2(100)$ & 2.03 & 0.36 \\
\hline \multicolumn{6}{|l|}{$\begin{array}{l}\text { Water storage using open and } \\
\text { wide containers }\end{array}$} \\
\hline Yes & $25(30.5)$ & $57(69.5)$ & $82(100)$ & & \\
\hline No & $88(26.4)$ & $245(73.6)$ & $333(100)$ & 0.55 & 0.45 \\
\hline \multicolumn{6}{|l|}{ Latrine type } \\
\hline Private & $67(25.6)$ & $195(74.4)$ & $262(100)$ & & \\
\hline Public & $25(29.4)$ & $60(70.6)$ & $85(100)$ & & \\
\hline Open field & $21(30.9)$ & $47(69.1)$ & $68(100)$ & 1.03 & 0.50 \\
\hline \multicolumn{6}{|l|}{ Latrine usage } \\
\hline Always & $80(26.7)$ & $220(73.3)$ & $300(100)$ & & \\
\hline Sometimes/not at all & $33(28.7)$ & $82(71.3)$ & $115(100)$ & 0.17 & 0.67 \\
\hline \multicolumn{6}{|l|}{ Hand washing habit } \\
\hline Present & $110(27)$ & $298(73)$ & $408(100)$ & & \\
\hline Absent & $3(42.9)$ & $4(57.1)$ & $7(100)$ & 0.88 & 0.34 \\
\hline \multicolumn{6}{|l|}{ Purpose for washing } \\
\hline Known & $87(25.4)$ & $256(74.6)$ & $343(100)$ & & \\
\hline Not known & $26(36.1)$ & $46(63.9)$ & $72(100)$ & 0.347 & 0.06 \\
\hline \multicolumn{6}{|l|}{$\begin{array}{l}\text { Dirty materials in the right hand } \\
\text { fingernails }\end{array}$} \\
\hline Present & $81(28)$ & $208(72)$ & $289(100)$ & & \\
\hline Absent & $32(25.4)$ & $94(74.6)$ & $126(100)$ & 0.31 & 0.57 \\
\hline Total & $113(27.2)$ & $302(72.8)$ & $415(100)$ & & \\
\hline
\end{tabular}

${ }^{*}$ No intestinal helminth ova, larvae or adult seen

One hundred seventy-three $(41.7 \%)$ of the children complained of signs and/or symptoms related with parasitic intestinal infections. The most common complaints were abdominal cramp and abdominal pain$142(34 \%)$, vomiting and nausea- $62(14.9 \%)$, presence of "worm" in stool 44 (10.6\%), and diarrhoea- 40 (9.6\%). Sixty-nine $(61.1 \%)$ of the infected children reported the absence of any sign and/or symptom of intestinal parasitic infections.

Wasting (WHZ) was the predominant manefestation of malnutrition $11.6 \%$ (22 out of 190), followed by stunting (HAZ) 5.4\% (22 out of 404) and underweight (WAZ) $5.2 \%$ (21 out of 404). Boys showed a higher prevalence of wasting, stunting, and being underweight, than girls but the observed differences were not statistically significant $(\mathrm{p}>0.05)$.

This study has also analyzed the relationship between anthropometric scores and intestinal helminthic infections. The overall prevalence rate of intestinal helminthic infections was not different among children with or without stunting, wasting and underweight ( $>0.05$ ) (Figure 1). The prevalence of H. nana infection was $23.8 \%$ in stunted children and $9.4 \%$ in normally nourished children, and the difference was statistically significant $(p<0.05)$. Due to the low number of positive cases, it was not possible to analyze the effect of other intestinal helminthic infections on the anthropometric scores of the children. 
Table 3: Hookworm prevalence among Babile town schoolchildren, Eastern Ethiopia, 2001 Hookworm infection

\begin{tabular}{|c|c|c|c|c|c|}
\hline & $\begin{array}{l}\text { Yes } \\
\text { № (\%) }\end{array}$ & $\begin{array}{c}\text { No * } \\
\text { № (\%) }\end{array}$ & $\begin{array}{c}\text { Total } \\
\text { № (\%) }\end{array}$ & $\chi^{2}$ & P-value \\
\hline \multicolumn{6}{|l|}{ Shoe } \\
\hline Present & $26(6.5)$ & $371(93.5)$ & $397(100)$ & & \\
\hline Absent & $2(11.1)$ & $16(88.9)$ & $18(100)$ & 0.57 & 0.34 \\
\hline \multicolumn{6}{|l|}{ Protective shoe } \\
\hline Present & $18(6.3)$ & 267 (93.7) & $285(100)$ & & \\
\hline Absent & $8(7.1)$ & $104(92.9)$ & $112(100)$ & 0.09 & 0.76 \\
\hline \multicolumn{6}{|l|}{ Shoe wearing habit } \\
\hline Always & $8(3.9)$ & $199(96.1)$ & $207(100)$ & & \\
\hline Sometimes/ not at all & $20(9.6)$ & $188(90.4)$ & $208(100)$ & 5.45 & 0.01 \\
\hline
\end{tabular}

${ }^{*}$ No ova, larvae or adult of hookworm seen

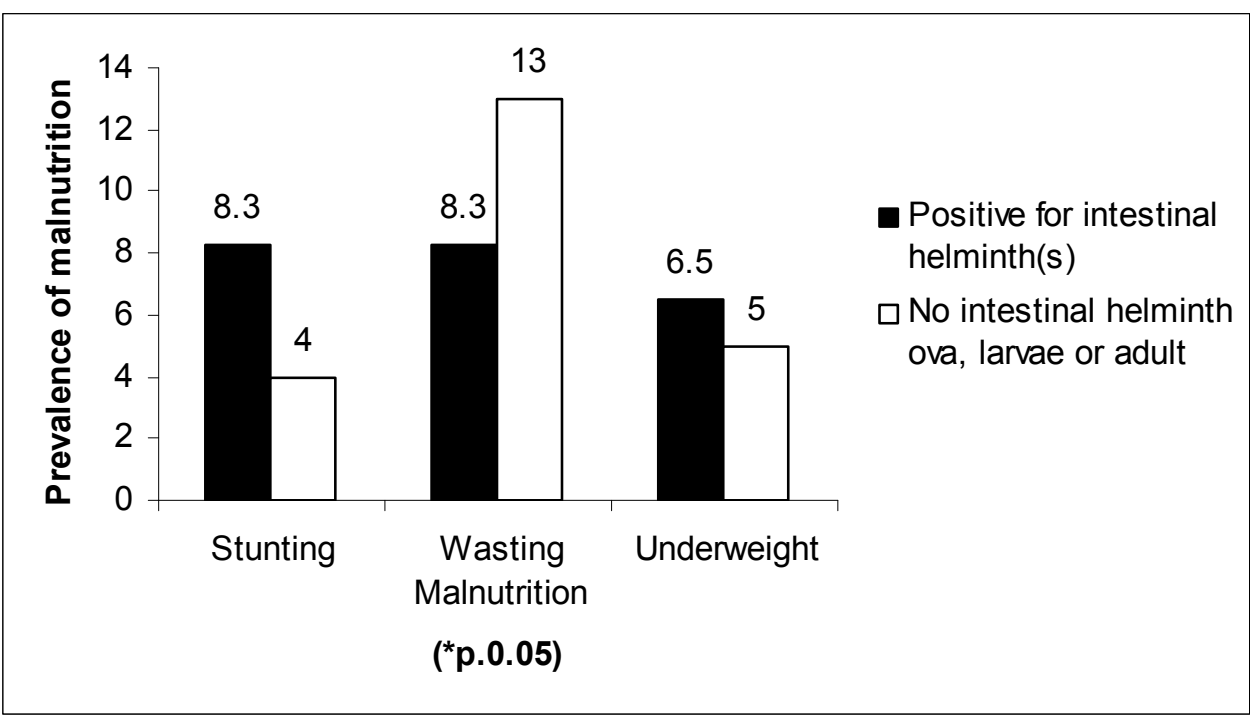

Figure 1: Prevalence of malnutrition and intestinal helminthic infections among Babile town school children, eastern Ethiopia, 2001

\section{Discussion}

Studies on estimated disease burdens show that globally, 39 million DALYs (disability-adjusted life years) lost due to intestinal helminthiasis. This model also estimated that $70 \%$ of the total burden of diseases is due to STH infections, which could be prevented in high-prevalence communities by treating school-age children (4). Knowledge on the distribution and extent of intestinal helminthic infections in a given community is thus a prerequisite for planning and evaluating intervention programs.

The present study also assessed the prevalence of intestinal helminthic infections their and associated local risk factors among schoolchildren in Babile town. In this study, the observed overall prevalence rate was found to be relatively lower than studies done elsewhere in Ethiopia $(12,15,16,25)$. The same trend was also documented for polyparasitism $(25,26)$. A study from southern Ethiopia showed higher overall prevalence
(89\%) and double infection rates (35.4\%) than those found by the present study (25). The prevalence observed by the present study is lower than the reported prevalence for the eastern Ethiopian region (45.9\%) (15). The prevalence rate of intestinal helminthic infections in Babile, determined by the present study, is comparable with the year 1986 Lo et al report rate for Bisdimo district in Afar Region but higher than the rate for Jijiga town in south eastern Ethiopia (15).

H. nana had a prevalence rate of $10.1 \%$. This was higher than the findings of Belye and Solomon (1.1\%) (25), Tsehai et al (1.3\%) (16) and Lo et al (2.8\%) (15), but six times lower than among schoolchildren in Kemise town in North Ethiopia (61\%) (27).

In the present study, hookworm was found to be the dominant STH (6.7\%), followed by A. lumbricoides $(4.3 \%)$ and T. trichiura (3.9\%). studies from Southern Ethiopia by Ibrahim et al (17) and Belay and Solomon 
(25) used the same concentration technique but reported higher rates of hookworm $(25.5 \%$ and $17 \%), A$. lumbricoides $(56.4 \%$ and $75.2 \%)$ and T. trichiura $(21.6 \%$ and $24.4 \%$ ), respectively.

The differences in findings among the studies can be explained by variations in geography, socio-economic conditions, and cultural practices of the population under consideration. The category of the study population, the methods employed for stool examination, and the time of study may also have contributed to the differences.

In 1989, the Malaria and Other Vector Borne Disease Control Program (MOVBDCP) of the Ministry of Health conducted an $S$. mansoni survey using the Kato-katz technique (14). According to the survey $43(43 \%)$ of the schoolchildren from Babile town were found to be positive for S. mansoni eggs (14). In spite of the more sensitive technique used in the present study, the prevalence was ten times lower than the report. Lack of information such as the sampling technique and the study season has hindered a precise comparison of the results. However, considering the sample size and the techniques used in the present study, it is tempting to conclude that this impressive drop in prevalence rates might have been followed by improvements in the general standards of living of the people. However, further studies had to be conducted before reading at such conclusions.

In this study, $99.6 \%$ of the schoolchildren had access to safe drinking water $84 \%$ of them had access to latrine facilities. Only $30 \%$ of the schoolchildren in Asendabo district in south western Ethiopia had access to safe drinking water and $32 \%$ of them had no latrine facilities (17). In south Wollo, $40 \%$ of the schoolchildren here found to have no latrine and $26.8 \%$ of them used unsafe water for domestic purposes (16). On the other hand, $95.7 \%$ of the schoolchildren in Babile town wore shoes and $52 \%$ wore them regularly, but only $59.6 \%$ of Asendabo schoolchildren had shoes and a mere $24 \%$ of them wore shoes on a regular basis (17). The above facilities, as well as other factors, might have contributed for the low prevalence of intestinal helminthiasis among Babile schoolchildren.

Most of the schoolchildren had dirt in their fingernails. It would have been interesting in this study to analyze the fingernail contents and digit sucking habit of the children. However, it is important to examine the role of dirty fingernails in the hand to mouth transmission of parasites.

It was expected that there would be lower prevalence rates of overall and H. nana infections among private or public latrine users than that of the schoolchildren who defecate in the open fields. However, no significant difference in prevalence among the three groups was observed ( $p>0.05)$. This is also in line with other studies done elsewhere in Ethiopia (16,17). The quality and usage of the latrines might explain the unexpected findings.

It seems that the regular wearing of shoes has a significant contribution to the low prevalence rate of hookworm infections $(p<0.05)$. Health education on disease transmission and encouraging children to wear shoes regularly may contribute to the prevention and control of hookworm and parasites with similar modes of transmission.

The prevalence of $S$. mansoni infection was found to be significantly higher in boys than in girls $(p<0.05)$ and this gender-associated difference has also been found in other studies $(15,16)$. The existence of more outdoor activities among boys than girls could be one of the reasons for this finding. This observation is supported by the fact that none of the girls had any history of playing, fishing, or swimming in local water sources, which increase their exposure to cercarial-infested water.

In agreement with a previous study done in Ethiopia (11), anthropometric scores were found to be independent of the overall rate of intestinal helminthic infections (Figure 1) $(p>0.05)$. However, a study done elsewhere has shown a higher prevalence of overall helminthic infections in stunted children compared to those in normally nourished children (10).

In the present study, H. nana infection was found to be more common among stunted children than normally nourished children $(p<0.05)$. This finding agrees with studies done among schoolchildren in Brazil (9), Mexico (10), and with an in-depth study done on Egyptian children (28). Symptoms seen in H. nana infections are generally less severe than by other causes of helminthic or protozoal diarrhoea, but are significantly associated with abdominal pain and gastrointestinal symptoms (29). It has also been suggested that $H$. nana may cause epidemics in institutions for children (29). H. nana infection is therefore an important topic for public health particularly in communities with high prevalence rates of the parasites.

Finally, past experience has shown that intervention programs can bring about a significant decrease in intestinal parasitic infection rates within a short period of time (30). Such declines in prevalence rates are heartening, and thus school-based prevention and control programs should be strengthened.

\section{Acknowledgements}

This study was financial supported by the Ethiopian Science and Technology Commission. The Alemaya University provided logistical support and proper working conditions for the smooth running of this study. I am grateful to the Babile school community and staff of 
Babile Health Center for their enthusiastic cooperation. I also thank Mr. Melake Damena and Dr. Diwakar Tejaswi, Mr. Tegegne Sishaw and Mr. Solomon Demissie for their material support.

\section{References}

1. World Health Organization. Informal consultation on intestinal helminthes infection. WHO, Geneva, Switzerland July 9-12, $1990 \quad$ (document WHO/CDS/IPI/90.1).

2. World Health Organization. Basic laboratory methods in medical parasitology. Geneva: WHO, Geneva, Switzerland 1991:-32.

3. World Health Organization. Prevention and control of schistosomiasis and soil-transmitted helminthiasis. WHO technical report series 912. WHO, Geneva, Switzerland 2002.

4. Chan MS. The global burden of intestinal nematode infections-fifty years on. Parasitol Today. 1997;13:438-443.

5. De Silva NR, Guyatt HL, Bundy DA. Morbidity and mortality due to ascaris-induced intestinal obstruction. Trans R Soc Trop Med Hyg. 1997;91:31-36.

6. Stephenson LS, Latham MC, Adams EJ, Kinoti SN, Pertet A. Physical fitness, growth and appetite of Kenyan school boys with hookworm, Trichuris trichiura and Ascaris lumbricoides infections are improved four months after a single dose of albendazole. J Nutr. 1993;123:1036-1046.

7. Nokes C, Bundy DA. Compliance and absenteeism in schoolchildren: Implications for helminth control. Trans R Soc Trop Med Hyg. 1993;87:148-152.

8. Hadidjaja P, Bonang E, Suyardi MA, Abidin SA, Ismid IS, Margono SS. The effect of intervention methods on nutritional status and cognitive function of primary school children infected with Ascaris lumbricoides. Am J Trop Med Hyg. 1998;59:791795.

9. Tsuyuoka R, Bailey JW, Nery Guimaraes AM, Gurgel RQ, Cuevas LE. Anaemia and intestinal parasitic infections in primary school students in Aracaju, Sergipe, Brazil. Cad Saude Publica. 1999;15:413-421.

10. Quihui-Cota L, Valenica ME, Crompton DWT, Phillips S, Hagen P, Diaz-Camacho SP, Tejas AT. Prevalence and intensity of intestinal parasitic infections in relation to nutritional status in Mexican schoolchildren. Trans R Soc Trop Med Hyg. 2004;98:653-659.

11. Asfaw TS, Goitom L. Malnutrition and enteric parasitoses among under-five children in Aynalem village, Tigray. Ethiop J Health Dev. 2000;14:67-75.

12. Legesse M, Erko B. Prevalence of intestinal parasites among schoolchildren in a rural area close to southeast of Lake Langano, Ethiopia. Ethiop J Health Dev, 2004;18:116-120.
13. Jemaneh L. The epidemiology of Schistosomiasis mansoni and soil-transmitted helminths in elementary school children from the south Gonder zone of Amhara National Regional State, Ethiopia. Ethiop Med J. 2000;38:105-118.

14. Birre H, Tedela S, Tilahun G, Kloos H, Eshete H. Schistosomiasis and its distribution in Ethiopia and Eritrea. In: Birre H, Tedela S, Jemaneh L, (editors). Schistosomiasis in Ethiopia and Eritrea. 2nd ed. Addis Ababa University Press, Addis Ababa, Ethiopia 1998. p. 37.

15. Lo CT, Ayele T, Birre H. Helminth and snail survey in Harerge region of Ethiopia with special reference to schistomiasis. Ethiop Med J. 1989;27:73-83.

16. Assefa $\mathrm{T}$, Woldemicheal $\mathrm{T}$, Dejene $\mathrm{A}$. Intestinal parasitism among students in three localities in south Wello, Ethiopia. Ethiop J Health Dev. 1998;12:231235.

17. Ali I, Mekete G, Wodajo N. Intestinal parasitism and related risk factors among students of Asendabo elementary and junior secondary school, south western Ethiopia. Ethiop J Health Dev. 1999;13:157161.

18. Merid Y, Hegazy M, Mekete G, Teklemariam S. Intestinal helminthic infection among children at Lake Awassa area, south Ethiopia. Ethiop J Health Dev. 2001;15:31-37.

19. The Regional state of Oromiya Office for Planning and economic development for eastern Hararghe zone. Statistical Abstracts 1999/2000. Harar, Ethiopia 2001.

20. The Regional state of Oromiya, eastern Hararghe Administrative Zone Office for Planning and economic development. Socio-economic profiles of Babile district 1995/96- 1996/97. Harar, 1998.

21. Daniel WW. Biostatistics a foundation for analysis in the health science. 6th ed. New York: John Willey \& Sons Inc, New York, USA. 1995. p.155.

22. Gorstein J, Sullivan K, Yip R, Onis M.de, Trowbridge F, Fajans P, Clugston G. Issues in the assessment of nutritional status using anthropometry. WHO Bull. 1994;72:273-283.

23. Statistical Package for Social Scientists (SPSS) Version 11, SPSS Inc, Chicago, USA 2001.

24. Dean AG, Dean JA, Coulombier D, Brendel KA, Smith DC, Burton AH et al. Epi Info. Version 6: A word-processing, database, and statistics program for epidemiology on microcomputers: CDC, Atlanta, USA. 1994.

25. Roma B, Worku S. Magnitude of Schistosoma mansoni and intestinal helminthic infections among school children in Wondo-Genet zuria, southern Ethiopia. Ethiop J Health Dev. 1997;11:125-129.

26. Jemaneh L. Schistosomiasis mansoni and geohelminthiasis in school children in the Dembia plains, northwest Ethiopia. Ethiop J Health Dev. 1998;12:237-244. 
27. Kloos $\mathrm{H}$, Tesfa-Yohannes $\mathrm{T}$. Intestinal parasitism. In: Kloss H, Zein AH, editors. The ecology of health and disease in Ethiopia. Westview Press, Colorado, USA. 1993. p. 223-233.

28. Khalil HM, el Shimi S, Sarwat MA, Fawzy AF, el Sorougy AO. Recent study of Hymenolepis nana infection in Egyptian children. J Egypt Soc Parasitol 1991;21:293-300.
29. Mirdha BR, Samantray JC. Hymenolepis nana: A common cause of paediatric diarrhoea in urban slum dwellers in India. J Trop Pediatr 2002;48:331-334.

30. Tadesse G. Patterns of infection by intestinal parasites at Shebe Training Health Center, southwest Ethiopia. Proceedings of the 38th Ethiopian Medical Association (EMA) Annual Medical Conference; 2002 June 5-7; Addis Ababa, Ethiopia. 

